\title{
Versatile Classroom Management Solution for Teachers in Developing Countries
}

\author{
Muhammad Zahid Iqbal \\ Information Technology University, Lahore, Pakistan \\ Hello.Zahideoutlook.com
}

\begin{abstract}
Bringing interactivity and effectiveness of teaching in the classroom is always challenging especially in the developing countries. Previous studies show best practices of smart technologies in the classroom.

This research was conducted to develop an efficient and low-cost solution for teachers in managing the higher number of students, assessing progress and increasing student engagement in the classroom. We developed My Class Manager; a Smartphone application for quiz and paper marking, audio quiz for native language learning and performance management throughout the semester. We conducted a series of five evaluations of three classes of sizes 30,35 and 40 . Results of the evaluations show an increasing interest of students in the classroom, improved class engagement $\&$ attentions. It creates a time-efficient learning environment.
\end{abstract}

\section{Keywords:}

ICT in education, m-learning, smart education, Smartphone interactions, teaching methodologies, e-learning, interaction methodologies, Human Centered Design.

\section{Introduction}

Education in the developing countries and rural areas is always a problem due to lack of resources and teachers. Due to large classes' size, teachers enable to provide attentions to students which lead to poor performance.

Smart phones are integrating rapidly in the lives there is a big move towards the implementing these applications in the education. Distance learning has been totally changed with these applications [1]. Lots of students' engagement strategies are being adopted in the different countries which definitely bring results to a great extent [2, 12]. Singapore \& Australia have brilliant experience of ICT based solution in the early classes' school education and really get appreciated results $[6,10]$.

Wankel \& Charles worked for students' engagement in the classroom by using the latest technology. They worked with the social media, communication mediums and web 2.0 to bring an innovation in the classroom environment [3].

Tondeur, Jo, and et al have worked out to find how ICT interact with the policy of the schools. They have shown their finding as it is hard to implement any new technology in the classroom in the public sector because of policy restrictions [4]. Sutherland and 
Rosamund have worked out to find the efficiency of use of ICT in the classroom and outside the classroom [5].

Choy and Doris Wong have briefly explained what is happening in the classroom in Singapore. They have explored the smart classroom of the Singapore which delivers best results in the World [6].

Jung, and Insung worked with ICT-Pedagogy integration in the teachers training workshop to deliver the best practices and providing ICT experience for teachers [7]. Kennewell and Steve worked on learning outcomes from a technology rich classroom environment for teachers. They have explored the benefits of technology on learning and teaching with ICT-based pedagogy [8].

Markett, and Carina have introduced an SMS based system to create interactivity in the classroom where students get involved with SMS with instructors [9]. Meurant, and Robert have also used SMS teaching methodology which provides quite successful results [11]. This method also adopted in Pakistan which is SMS based quiz system.

Mertler, Craig A., and Cynthia Campbell developed Assessment Literacy Inventory (ALI) and evaluated with 152 teachers to find the performance of traditional teaching methods and new interventions of technology in teaching pedagogy [10].

We conducted survey and interviews to find and explore the local challenges. Despite all of the above mentioned great inventions. In the public sector schools, Classes size is too big and teachers vs. students ratios highly low. It creates a gap between delivery of knowledge and time efficiency. There is a need of a comprehensive solution for the classroom which can help teachers to conduct quiz and make assessment easily.

\section{Proposed Solution}

We developed a smart phone application for teachers named My Class Manager for Android OS devices. Android is one of the most popular OS used in smart phones in Pakistan as more than $90 \%$ Smart phones are Android OS based.
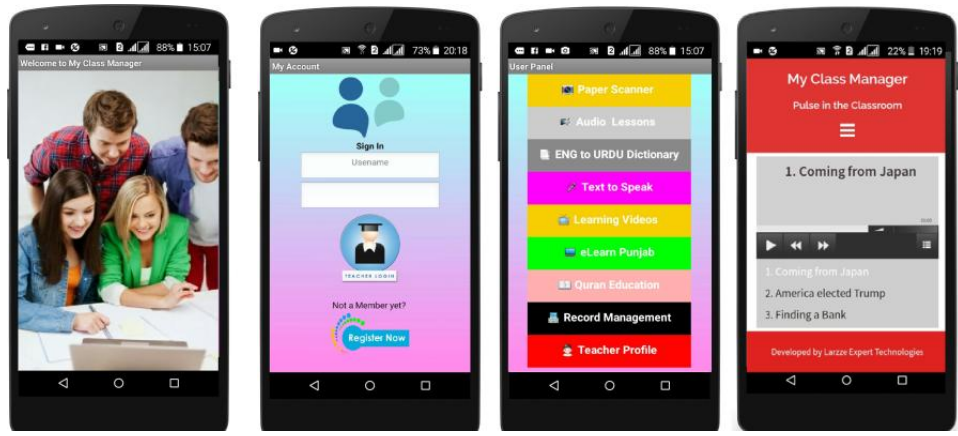

Fig. 1. Right to Left, Splash Screen, Login Screen Dashboard and audio quiz of Application 
Basic interface has been shown in Fig. 1. A server is linked with the Android application where teachers can create their quiz/papers and conduct in the classroom. Teachers provide the answer sheets to the students and play the audio quiz in the classroom.

In the concept of the audio quiz teacher enables to manage a large class size by creating attention and delivering the quiz with native English language accent. Teachers can make their digital quiz anytime in the class and conduct for students.

After finishing the quiz time, teacher will scan the answer sheets of all the students through application. Application sends scanned answer sheets to server \& provides the results on the base of correct answers. Application provides text to speak, English to Urdu and Urdu to English dictionary to help teachers in the native English accent which is lack in the Pakistan.

\section{EVALUATIONS}

Application tested in three different classes. These tests conducted in $6^{\text {th }}, 7^{\text {th }}$ and $8^{\text {th }}$ class with 40 students each. A Smartphone given to every teacher with application installed inside and guided about the testing procedure of the application. There were Eight (3) teachers who participated in the testing. Students participated in the research are 12-16 years old. Teachers participated in the research have 3-7 years experience in teaching English and science subjects.

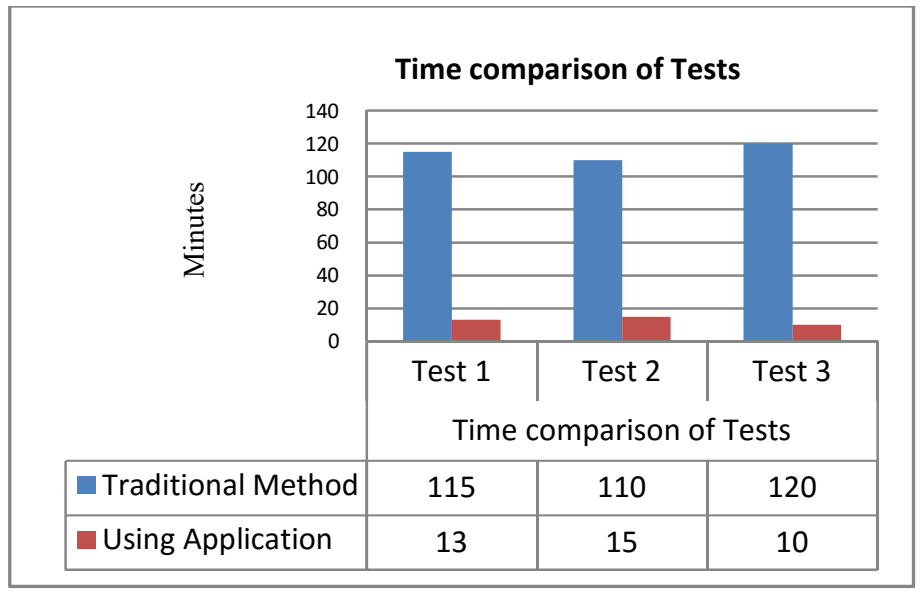

Fig. 2. This graphs shows evaluations conducted in the three classes

As checking a manual papers/quiz manually takes $80-120$ Minutes for 20 one page MCQs papers. Using the My Class Manager teachers checked 40 papers within Ten 10-15 minutes, show in Fig. 2. It saved about two hours just for simple paper which test the students' performance easily and provided whole class average results without any effort. As explained by teacher who has about seven years experience in teaching English says, "I am teaching 55 students and it is not possible for me to provide indi- 
vidual attentions and conducting students' assessment by paper work due to large class size."

\section{Conclusion}

Teachers show a great attraction towards using ICT in classroom for making their life easier and using modern teaching pedagogy. Teachers show a great attraction towards using ICT in classrooms for making their life easier and using modern teaching pedagogy. Paper \& Quiz checking speed and getting full assessment of the large class size is highly improved which is one of the basic need for teachers. As for generating progress reports for parents and management of students' data for the whole years need lots of time with manual working, My Class Manager can do this work without any effort.

In the further investigation, we are working to approve the application by adding new features which can create more interactive classroom environment.

\section{$5 \quad$ References}

1. Paris, Scott G., and Alison H. Paris. "Classroom applications of research on self-regulated learning." Educational psychologist 36.2 (2001): 89-101.

2. Christenson, Sandra L., Amy L. Reschly, and Cathy Wylie, eds. Handbook of research on student engagement. Springer Science \& Business Media, 2012.

3. Wankel, Charles, and Patrick Blessinger. Increasing student engagement and retention in e-learning environments: Web 2.0 and blended learning technologies. Vol. 6. Emerald Group Publishing, 2013.

4. Tondeur, Jo, et al. "ICT integration in the classroom: Challenging the potential of a school policy." Computers \& Education 51.1 (2008): 212-223.

5. Sutherland, Rosamund, et al. "Transforming teaching and learning: embedding ICT into everyday classroom practices." Journal of Computer Assisted Learning 20.6 (2004)

6. Choy, Doris, Angela FL Wong, and Ping Gao. "Singapore's preservice teachers' perspectives in integrating information and communication technology (ICT) during practicum."

7. Jung, Insung. "ICT-Pedagogy Integration in Teacher Training: Application Cases Worldwide." Educational Technology \& Society 8.2 (2005): 94-101.

8. Kennewell, Steve, and Gary Beauchamp. "The influence of a technology-rich classroom environment on elementary teachers' pedagogy and children's learning." Proceedings of the international federation for information processing working group 3.5 open conference on Young children and learning technologies-Volume 34. Australian Computer Society, Inc., 2003.

9. Markett, Carina, et al. "Using short message service to encourage interactivity in the classroom." Computers \& Education 46.3 (2006): 280-293.

10. Mertler, Craig A., and Cynthia Campbell. "Measuring Teachers' Knowledge \& Application of Classroom Assessment Concepts: Development of the." Online Submission (2005).

11. Meurant, Robert C. "Cell Phones in the L2 Classroom: Thumbs up to SMS."2006 International Conference on Hybrid Information Technology. Vol. 1. IEEE, 2006.

12. Lindquist, David, et al. "Exploring the potential of mobile phones for active learning in the classroom." ACM SIGCSE Bulletin. Vol. 39. No. 1. ACM, 2007. 